\title{
Family planning in the Toledo District of Southern Belize: survey of knowledge, contraceptive use, and preferences
}

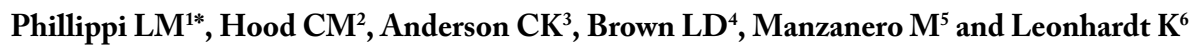 \\ ${ }^{1}$ Assistant Professor, Children's Hospital of Wisconsin; Milwaukee, Wisconsin, USA \\ ${ }^{2}$ Clinic and Public Health Director, Hillside Health Care International; Eldridgeville, Belize, USA \\ ${ }^{3}$ Assistant Professor, UW-Madison School of Medicine and Public Health, Department of Obstetrics \& Gynecology; Madison, Wisconsin, USA \\ ${ }^{4}$ Associate Director, UW- Madison Global Health Institute; Madison Wisconsin, USA \\ ${ }^{5}$ Director of Health Services, Ministry of Health Belize, Belmopan, Belize, USA \\ ${ }^{6}$ Consultant, Joint Commission International, Belmopan, Belize, USA
}

\begin{abstract}
Introduction: Family planning improves maternal and child health and is a public health priority. In Belize, contraceptive prevalence is lowest in the Toledo District. Unmet need for contraception in the Toledo District is double that of Belize. Aims of this study were to determine women's knowledge, current and past use, and preferences for family planning in the Toledo District, Belize.

Methodology: We conducted one-on-one semi-structured interviews with a convenience sample of 110 women of childbearing age (15-44 years) who presented for care at Hillside Health Care International's main clinic, eight mobile clinics, during six home visits, and three community health fairs.

Results: Women were predominantly Mayan (80.9\%), married (48.1\%) or in common-law relationships (30.9\%), and had one (30.9\%) or 2-4 (28.2\%) children. Only $36.8 \%$ of women reported ever having had contraceptive options explained to them by a health care provider. Less than half of women were aware of the etonogestrel implant (41.8\%), intrauterine devices (22.7\%), and female sterilization (6.3\%). 58.1\% were currently using family planning and 76.4\% had ever used family planning. Of women who expressed preference, women preferred injectable progesterone (40.6\%), the etonogestrel implant (20.8\%), and oral contraceptive pills (18.8\%), and less preferred IUDs (6.9\%) and female sterilization (2\%).
\end{abstract}

Discussion: Knowledge of modern methods of contraception is low among women of the Toledo District, as is uptake of long-acting reversible and permanent methods of contraception. Provider and systems-based opportunities exist to increase contraceptive knowledge and uptake in the region.

\section{Introduction}

Family planning promotes improved maternal and child health outcomes and is a public health priority. Safe birth intervals are linked to decreased maternal mortality, decreased infant mortality and decreased under-5 mortality [1]. Births spaced at least 36 months apart are associated with the lowest mortality risk, while birth to conception intervals of fewer than 6 months are associated with increased risk of maternal mortality and morbidity, increased risk of pre-term births, low birth weight, and small for gestational age infants [2]. Further, family planning is an important intervention shown to improve child and maternal nutrition status and improve access to girls' education [3].

Despite calls for universal access to reproductive health services, women throughout much of the developing world remain disempowered by lack of access to birth control [4]. Though measures of unmet need for family planning (women want to stop or delay childbearing but are not using any method of contraception) are often based on married women of childbearing age, research has shown a substantial unmet need in younger, low-parity, and zero-parity women [5]. To see substantial improvement in maternal and child health, the right to reproductive health care including access to modern contraceptive methods must be fulfilled and protected.

Throughout Latin America, though contraceptive prevalence has risen substantially, unmet need for contraception remains high. In Belize, contraceptive prevalence rose from $34.3 \%$ in 2006 to $55.2 \%$ in 2011 but contraceptive prevalence was lowest in the Toledo District at $28.3 \%$ [6]. While unmet need for contraception was $15.9 \%$ for Belize unmet need was more than double that in the Toledo District at $32.9 \%$ [7]. The percentage of women in Belize whose demand for contraception is satisfied was $77.6 \%$, compared to the Toledo district which was lowest at $46.3 \%[8,9]$. The Multiple Indicator Cluster Survey was updated in 2015 but complete results including district comparisons have not yet been published. The key findings report does show that for the country of Belize $48.5 \%$ of women are utilizing modern methods of contraception, $2.9 \%$ are using traditional methods and $48.6 \%$ are using no method of contraception [10]. Special attention to the Mayan population is warranted as the population of the Toledo district is $66.5 \%$ Mayan (compared to $11.3 \%$ of the total population of Belize) [10]. In a qualitative study of predominantly Mayan women in

Correspondence to: Leah M Phillippi MD, MPH, Midtown Pediatrics, Assistant Professor, Children's Hospital of Wisconsin; Milwaukee, Wisconsin, USA, Tel: (414)277-8900; E-mail: lphillippi@chw.org

Key words: contraception, family planning, Central America, Belize

Received: April 16, 2017; Accepted: May 30, 2017; Published: June 03, 2017 
the San Ignacio region of Belize, authors reported that women faced many barriers to planning pregnancies including lack of knowledge of contraceptive methods, partners seeking control over women, religious and cultural beliefs, and opposition of family members [11].

In 2010, the Toledo district experienced neonatal (14.4/1000), infant $(22.3 / 1000)$ and under-5 (31.9/1000) mortality rates nearly twice that of Belize as a whole $(8 / 1000,13.3 / 1000,16.9 / 1000$ respectively) $[12,13]$. Every year from 2006 to 2010, complications of pregnancy, childbirth and the puerperium were the leading causes of hospitalization in Belize among 15-19-year-old girls and they remain the leading causes of hospitalizations among 10-14-year-old girls [14]. The rate of teenage marriage is highest in the Toledo District with $11.1 \%$ of girls married prior to age 15, twice the Belize rate of 5.6\% [15]. 2006 data show twice as many children age $0-59$ months in the Toledo district (11.2\%) have low weight for age compared to Belize overall (6.1\%) and more than twice as many children age $0-59$ months $(42.7 \%)$ have low height for age compared to Belize overall (17.6\%) [12]. A 2011 update confirms that Toledo experiences high rates of underweight $(7.4 \%)$ and stunting (41.6\%) compared to the rest of Belize $(6.2 \%, 41.6 \%)$ [8].

Hillside Health Care International (HHCI) is a non-governmental organization (NGO) located in Punta Gorda, Belize, that partners closely with the Belize Ministry of Health $(\mathrm{MoH})$ to provide primary healthcare including contraceptives in the Toledo District. The Belize national health insurance plan and the overall public health sector in Belize provide all citizens with free or low cost access to primary care and medications including contraceptives on the national formulary $[15,16]$. However, access to and the supply of contraceptives are sometimes insufficient to meet the demands of the population [9]. While the Belize Multiple Indicator Cluster Survey comprehensively covers prevalence of contraception use, methods used and unmet need per district, further information including women's knowledge of contraceptive methods, preferences and perceived barriers is not included. This paper describes results of a voluntary family planning semi-structured interview and needs assessment of women in the rural Toledo District of southern Belize. Aims of the study were to determine women's knowledge, current and past use, and preferences for family planning methods. The study results will be used to improve the scope and quality of family planning services provided in the Toledo district through the partnership between HHCI and the Belize $\mathrm{MoH}$.

\section{Methods}

In collaboration with Belize's $\mathrm{MoH}$, we developed a one-on-one, semi-structured interview tool to assess women's knowledge, current and past use, and preferences for family planning services. Interview guide items were initially adapted from a prior survey conducted in San Ignacio Belize and modified utilizing questions from Child Survival and Health Grants Program's validated Knowledge Practices and Coverage Surveys on Pregnancy Spacing and Family Planning [11,17]. The Clinic Director and Public Health Director at HHCI and the Director of Health Services at the Belize $\mathrm{MoH}$ modified and approved the final semi-structured interview guide (Table 1). Institutional

Table 1. Interview questions.

\section{Demographics:}

In what year were you born?

Which [ethnicity] best describes you?

What is your marital status?

How many children do you have?

What village do you live in?

Family Planning:

What family planning methods have you heard of?

Are you currently doing something or using any method to delay or avoid getting pregnant?

Which family planning method are you using/have you used?

Where did you obtain [your family planning method] the last time?

Where are the places that you have obtained any family planning service?

Were you satisfied with the family planning services that were provided?

What is/would be your preference for where to obtain family planning services?

Why do you prefer to receive family planning services there?

Are you satisfied with using [current method]?

Why did you select [current method]?

Was your husband involved in the decision to use family planning?

Additional questions for women who are not currently utilizing family planning, but did previously:

For how long did you use [previous family planning method]?

What caused you to stop [previous family planning method]?

Additional question for women who have never utilized family planning:

What are your reasons for not using a family planning method?

For all women:

Have you ever received a talk from your health care provider about family planning?

Which method would you prefer to use [options given: oral contraceptive pills, implant (Implanon), intrauterine device (IUD), injectable progesterone (shot), condoms, rhythm method, other]?

Why is that your preferred method?

What are the barriers to using other methods?

Have you ever come to a clinic for contraceptives and what you wanted was not available?

If yes, which clinic?

If yes, which contraceptive method did you want at that time?

In your opinion, is there an ideal time to wait after giving birth or after a miscarriage or abortion before attempting to become pregnant again?

What is the ideal length of time?

What are the benefits of waiting [specific time frame answered above] after giving birth, miscarrying or having an abortion before attempting to become pregnant again? 
Review Board (IRB) approval was received from both University of Wisconsin Madison in the United States and Belize's MoH before study commencement. A pilot study could not be completed due to the time frame of the approval process and the time that the lead researcher was in Belize.

Women seeking care at HHCI were approached by a trained interviewer from the study team and asked if they were willing to participate in a brief interview. The women were identified while seeking care at one of several HHCI locations in the Toledo District of Southern Belize: the home clinic, eight mobile clinics, six home visits, and three community health screening events. (Two of the health screening events were conducted by HHCI in Punta Gorda town square and one was conducted by Peace Corps Belize Volunteers in a remote village.) Investigators conducted one-on-one interviews with a convenience sample of 110 women of childbearing age (1544 years, as identified by the CDC between May 14, 2015, and June 19,2015 [18]. Responses to interview guide items were recorded on paper or electronically using the same interview guide instrument. As stipulated by the $\mathrm{MoH}$, women under 18 years of age required parental permission to be interviewed. Interviewers obtained informed consent verbally and documented consent on the interview form for each participant. The Lead Researcher (LP) conducted most interviews $(87.3 \%)$ and HHCI students and volunteers conducted remaining interviews (12.7\%) after being trained by the lead researcher to decrease inter-interviewer variability. Participants were offered an in-person interpreter. Though majority of interviews were conducted in English, 15.5\% of interviews were conducted with an in-person translator. Questions were open-ended and were all coded after by the lead researcher to ensure no inter-coder variability. The only exception was when women were asked which method they would prefer, in this case options were given and explanations were provided if the woman was unfamiliar with a method. Qualitative information volunteered by women during the interviews was also documented on the paper or electronic interview guide form. Responses were de-identified and entered an excel document for analysis.

\section{Results}

As shown in Table 2, of the 110 interviews, 35 (31.8\%) were conducted at HHCI's home clinic in Eldridgeville (near the Toledo
District's hub city, Punta Gorda), 53 (48.1\%) took place on HHCI's mobile clinics in rural villages in the Toledo District, and $22(20.0 \%)$ took place at one of the three health fairs. The women interviewed were of the following race/ethnicity: Mayan (80.9\%), Garifuna (5.4\%), East Indian (6.3\%), Creole (1.8\%), Mestizo (0.9\%) and other (4.5\%). Most women were either married (48.1\%) or in common-law relationships (30.9\%). 20.9\% of women reported they were single/never married. Twenty percent of the women interviewed had no children (though $27.2 \%$ of these women were currently pregnant), $30.9 \%$ had one child, $28.2 \%$ had $2-4$ children and $20.9 \%$ had five or more children.

\section{Knowledge and beliefs}

As shown in Table 3, when asked which family planning methods they had heard of, women were most aware of injectable depot progesterone contraception (87.2\%) followed by contraceptive pills (80.9\%). Knowledge regarding other methods was limited: less than half of women were aware of implantable contraception (etonogestrel implant) (41.8\%), condoms (37.3\%), intrauterine devices $(22.7 \%)$, the rhythm/cycle beads method (10\%), and female sterilization $(6.3 \%)$. Fewer than $5 \%$ of women reported awareness of female condoms, diaphragm, foam/jelly, contraceptive patch, or other methods. Only $36.8 \%$ of women reported ever having a health care provider discuss their family planning options with them.

$80.0 \%$ of women interviewed $(n=82)$ responded that there is an ideal time to wait between pregnancies. Most women felt waiting longer between pregnancies was preferred. 7.3\% reported that the ideal time to wait was less than a year, $23.2 \%$ reported $1-3$ years, and $69.5 \%$ reported an ideal time to wait of 3 or more years between pregnancies. When asked to describe reasons to wait between pregnancies, women cited the following: young children are difficult to take care of (33.6\%), wanting the youngest child be old enough to care for themselves before having another child (24.5\%), maternal health and recovery after birth (19.1\%), financial difficulty with having many children (13.6\%), having the time to bond with a child before having another (10.9\%), child health $(9.1 \%)$, maternal opportunity to get a job or education (5.5\%), and general medical riskiness of pregnancy and childbirth $(2.7 \%)$. Few women reported there being no benefits to waiting between pregnancies (5.5\%) while more women felt waiting was important but could not describe any benefits (12.7\%).

Table 2. Demographics of study participants.

\begin{tabular}{|c|c|c|c|c|c|c|c|c|}
\hline & $\begin{array}{l}\text { Mobile Clinics } \\
\mathbf{n}\end{array}$ & $\%$ & $\begin{array}{c}\text { Main Clinic } \\
\text { Eldridgeville n }\end{array}$ & $\%$ & $\begin{array}{c}\text { Health Fairs } \\
\text { n }\end{array}$ & $\%$ & Total n & $\%$ \\
\hline Total & 53 & $48.18 \%$ & 35 & $31.82 \%$ & 22 & $20.00 \%$ & 110 & $100.00 \%$ \\
\hline \multicolumn{9}{|l|}{ Ethnicity } \\
\hline Mayan & 48 & $90.57 \%$ & 26 & $74.29 \%$ & 15 & $68.18 \%$ & 89 & $80.91 \%$ \\
\hline Garifuna & 3 & $5.66 \%$ & 1 & $2.86 \%$ & 2 & $9.09 \%$ & 6 & $5.45 \%$ \\
\hline East Indian & 0 & $0.00 \%$ & 6 & $17.14 \%$ & 1 & $4.55 \%$ & 7 & $6.36 \%$ \\
\hline Creole & 0 & $0.00 \%$ & 1 & $2.86 \%$ & 1 & $4.55 \%$ & 2 & $1.82 \%$ \\
\hline Mestiso & 1 & $1.89 \%$ & 0 & $0.00 \%$ & 0 & $0.00 \%$ & 1 & $0.91 \%$ \\
\hline Other/Mixed & 1 & $1.89 \%$ & 1 & $2.86 \%$ & 3 & $13.64 \%$ & 5 & $4.55 \%$ \\
\hline \multicolumn{9}{|c|}{ Marital Status } \\
\hline Married & 32 & $60.38 \%$ & 14 & $40.00 \%$ & 7 & $31.82 \%$ & 53 & $48.18 \%$ \\
\hline Commonlaw & 13 & $24.53 \%$ & 15 & $42.86 \%$ & 6 & $27.27 \%$ & 34 & $30.91 \%$ \\
\hline Single & 8 & $15.09 \%$ & 6 & $17.14 \%$ & 9 & $40.91 \%$ & 23 & $20.91 \%$ \\
\hline \multicolumn{9}{|c|}{ Number of Children } \\
\hline 0 & 8 & $15.09 \%$ & 9 & $25.71 \%$ & 5 & $22.73 \%$ & 22 & $20.00 \%$ \\
\hline 1 & 11 & $20.75 \%$ & 19 & $54.29 \%$ & 4 & $18.18 \%$ & 34 & $30.91 \%$ \\
\hline 2 to 4 & 21 & $39.62 \%$ & 4 & $11.43 \%$ & 6 & $27.27 \%$ & 31 & $28.18 \%$ \\
\hline 5 or more & 13 & $24.53 \%$ & 3 & $8.57 \%$ & 7 & $31.82 \%$ & 23 & $20.91 \%$ \\
\hline
\end{tabular}




\section{Current and past use}

Over half the women $(58.1 \%)$ reported currently using a family planning method. As shown in Table 3, of the 64 women currently using contraception, the most common method reported was an injectable depot progesterone preparation $(53.1 \%)$, followed by oral contraceptive pills (17.1\%) and the etonogestrel implant (14.1\%). Few women relied primarily on condoms (7.8\%), had undergone female sterilization $(6.3 \%)$ or had an IUD currently in place (1.6\%). Of the 46 women not currently using a contraceptive method $11.5 \%$ indicated an interest in starting a method and $43.5 \%$ had used contraception in the past: $60 \%$ of them reported past use of oral contraceptive pills and $50 \%$ reported past use of injectable contraception. Of the 26 women $(23.6 \%)$ who had never used a family planning method, $46.2 \%$ did not give a reason for never using family planning. Amongst never-users who did cite reasons for not utilizing family planning, common reasons included concern about side effects (19.2\%), not being sexually active (11.5\%), trying to get pregnant (7.7\%), and lack of knowledge about family planning or how to access it (7.7\%).

Of current and past contraceptive users, $20 \%$ reported that their preferred method was not available at one point in the past when they had wanted it (experienced "stock-out"). Nearly $90 \%$ of stock-outs were of injectable contraception (87.5\%), though most women who reported experiencing a stock-out cited that they did receive an alternate form of injectable contraception when their preferred method was unavailable.

\section{Preferences}

When asked to name a preferred method of family planning, $91.8 \%$ of women interviewed $(n=101)$ named a method preference. As shown in Table 3, of women who expressed preference, women cited preference for injectable progesterone methods (40.6\%), the etonogestrel implant (20.8\%), and oral contraceptive pills $(18.8 \%)$, and less preference for IUDs (6.9\%), the rhythm method (6.9\%), condoms (5.9\%) and female sterilization (2\%). Among women citing a preferred contraceptive method, $80.2 \%(\mathrm{n}=81)$ responded when asked to describe reasons for selecting the preferred method. $34.6 \%(n=28)$ cited ease of use and $49.4 \%(n=40)$ wanted to avoid known/perceived side effects associated with other methods, including the fear of pain with injections or etonogestrel implant placement. Only two $(2.5 \%)$ women mentioned confidentiality (using contraception without her partner knowing) as a reason for preferring a specific method. Of note, all the included contraceptive options are on the $\mathrm{MoH}$ formulary and available at no cost to women.

Of current contraceptive users, $92.2 \%(n=59)$ reported that their partners were involved in the decision to begin family planning. Of past contraceptive users, $75 \%(n=15)$ reported their partner's involvement in the decision to begin family planning. $13.6 \%$ of women chose their preferred method of contraception based on wanting regular menses. $4.9 \%$ women mentioned that access was a consideration in their choice of preferred contraception, one woman (1.2\%) based her preference on religion, and two women (2.5\%) voiced lack of knowledge regarding other options.

All women interviewed were asked where they would prefer to receive family planning services in the future. Locations identified by the women included HHCI main and mobile clinic sites, $\mathrm{MoH}$ clinics, or through the public health nurse program. 48 women (43.6\%) responded that they would select their preferred location based primarily on proximity to their home A few women explained further that proximity to home was important as they saved money on bus fare $(n=6)$ and would not require that they travel with or leave their children $(\mathrm{n}=2)$.

While qualitative data were not collected in a formalized process, women expanded when asked open ended-questions. One woman shared that when the HHCI mobile clinic was out of injectable contraception, she was prescribed oral contraceptive pills instead. She was afraid to use the oral contraceptive pills after being counseled on the risks and became pregnant. Another woman was pregnant and share that she had initially been on oral contraceptive pills, but had stopped at the insistence of her partner who wanted a baby. A middleaged woman with eight children reported choosing her contraceptive method based on her ability to hide it from her partner. A few other women explained that family planning was their husband's idea. Several women in one village reported facing greater difficulty in accessing family planning due to transportation issues, as roads are regularly impassable during the rainy season

\section{Discussion}

Women interviewed in the Toledo District of Belize were overall most aware of injectable depot progesterone contraception and contraceptive pills, and less aware of other options including available Long Acting Reversible Contraceptive (LARC) methods (etonogestrel implant and intrauterine devices). Women felt that waiting between pregnancies was important, but few cited maternal or child health as reasons for longer inter-pregnancy intervals. Most of the women interviewed were currently using or had used contraception. In current and past contraceptive users, use of injectable depot progesterone and oral contraceptive pills was more frequent than etonogestrel implant, condoms, female sterilization or IUDs. While some women reported experiencing a stock-out, most could receive an alternate form of

Table 3. Contraceptive knowledge, experience and preference among study participants.

\begin{tabular}{|c|c|c|c|c|c|c|c|c|}
\hline \multirow{2}{*}{$\begin{array}{l}\text { Method } \\
\text { OCP }\end{array}$} & \multicolumn{2}{|c|}{ Awareness } & \multicolumn{2}{|c|}{ Current use } & \multicolumn{2}{|c|}{ Past use } & \multicolumn{2}{|c|}{ Preferred } \\
\hline & 89 & $80.91 \%$ & 11 & $17.19 \%$ & 12 & $60.00 \%$ & 19 & $18.81 \%$ \\
\hline Implant & 46 & $41.82 \%$ & 9 & $14.06 \%$ & 0 & $0.00 \%$ & 21 & $20.79 \%$ \\
\hline IUD & 25 & $22.73 \%$ & 1 & $1.56 \%$ & 0 & $0.00 \%$ & 7 & $6.93 \%$ \\
\hline Injectable & 96 & $87.27 \%$ & 34 & $53.13 \%$ & 10 & $50.00 \%$ & 41 & $40.59 \%$ \\
\hline Male Condom & 41 & $37.27 \%$ & 7 & $10.94 \%$ & 2 & $10.00 \%$ & 6 & $5.94 \%$ \\
\hline Rhythm & 11 & $10.00 \%$ & 0 & $0.00 \%$ & 0 & $0.00 \%$ & 8 & $7.92 \%$ \\
\hline Female sterilization & 7 & $6.36 \%$ & 4 & $6.25 \%$ & 0 & $0.00 \%$ & 2 & $1.98 \%$ \\
\hline Other & 12 & $10.91 \%$ & 0 & $0.00 \%$ & 0 & $0.00 \%$ & 0 & $0.00 \%$ \\
\hline
\end{tabular}

Notes:

- $\quad$ Other includes female condoms, abstinence, withdrawal, patch, foam, jelly, diaphragm and herbs

- $\quad$ Two of the women who report current condom use also reported using another method (injectable and implant)

- $\quad$ Only 101 women interviewed could name a preferred method 
contraception at that time. Women reported an overall preference for injectable progesterone, followed by etonogestrel implant and oral contraceptive pills. Preferences were based primarily on avoidance of side effects and ease of use. Very few women cited that their preference was due to confidentiality, while most women reported that their partners were involved in the decision making around using contraception. Women most frequently cited proximity to their home as the reason they chose where to receive family planning services.

The findings from this study regarding women's knowledge, experiences and preferences for contraceptive choices augment the existing literature and offer opportunities for improving contraceptive access for this population. The rates of contraception use in this study are higher than what had previously been reported in the literature for the Toledo District. The prevalence of contraception use may have increased from the reported data in 2011 to the time interviews were conducted in 2015, though this difference is likely the result of interviewing women who were seeking health services, as they are more likely to be using contraception. However, most women interviewed reported never receiving counseling on contraception options from a health professional. While the results of this study do not suggest an explanation to the discrepancy between the number of women who have used contraception and the number who have received counseling on options, it is likely that many women are prescribed a contraceptive without having had options explained to them.

While the Belize Multiple Indicator Cluster Survey is very comprehensive and the results of this study overlap in the areas of current contraception use and the desire to space pregnancies, this study expands on that information by exploring women's preferences for contraception, reasons for preferring a specific contraceptive method, and knowledge of contraceptive methods. This expanded information is essential for being able to develop programs and health services to better serve the needs of the community.

The novel findings of the study include qualitative findings regarding specific barriers in remote clinics, as well as confirmed expected low awareness of LARCs and low levels of counseling on reproductive choices. An opportunity exists to further integrate reproductive health care into routine primary care by expanding these conversations. It is a common perception that women prefer injectable progesterone contraception to preserve confidentiality from their partner, however this was not substantiated by this study. The findings point towards many couples making family planning decisions together and women knowing about the value of spacing pregnancies; there is more knowledge and agency in the community than presumed. Given the low awareness of modern methods of contraception, as well as the foundation of women who value spacing pregnancies and are making decisions with their partners, there is an opportunity to expand reproductive health education, and likelihood of success in focusing on awareness of and access to LARCs. This could be done through community outreach, educational and social marketing.

The semi-structured interview design of this study allowed for women to have a voice in the research and provided valuable and unique explanatory and contextual information. The value of this information highlights the importance of qualitative research and context specific information in the implementation of family planning programs. As women expanded on their reasons and knowledge, themes emerged which point to opportunities for improved care in the region. The focus on the population seeking care at HHCI also makes the findings valuable to that clinic, as well as to the $\mathrm{MoH}$, as $\mathrm{HHCI}$ is an important partner in providing care in the Toledo District. Specifically, the qualitative information gained through the interviews points towards a need to expand access to LARCs including etonogestrel implants to rural sites, and that it is imperative to recognize and address unique barriers that remote villages face when providing family planning and other health care services.

A limitation of the study is selection bias given convenience sampling and interviews largely conducted through HHCI clinic sites. This likely overestimate access to contraception, and may overestimate the degree to which partners make contraceptive decisions together, as most women were interviewed while seeking health care. There were no data collected on reasons for non-participation or demographics of women who declined to participate, so it is difficult to predict how this bias influences the interview results. As interviews were conducted orally, bias from illiteracy is minimized. Though all women were asked whether they preferred a translator, there is a potential that language barriers influenced results if women who declined translation had limited English fluency. It is also noted that while Sexually Transmitted Infections (STI) were minimally addressed as a part of this study, STI prevention, particularly HIV and the notions around it, is an important part of reproductive health considerations and how prevention of STIs influences family planning choices warrants further study in this population.

This study revealed that knowledge of most modern methods of contraception is low among women of the Toledo District, as is uptake of LARC and permanent methods of contraception. By increasing counseling from health professionals, integrating family planning services, including sterilization and LARC consistently into routine primary care, as well as through social marketing educational campaigns, there are provider and public health opportunities to increase contraceptive knowledge and demand in the region.

\section{Abbreviation}

\begin{tabular}{|c|c|c|}
\hline S.No. & Term & Meaning \\
\hline 1 & $\begin{array}{l}\text { Under-5 } \\
\text { mortality rate }\end{array}$ & $\begin{array}{l}\text { The number of children who die by the age of } \\
\text { five, per thousand live births per year. }\end{array}$ \\
\hline 2 & $\begin{array}{l}\text { Small for gestational } \\
\text { age }\end{array}$ & $\begin{array}{l}\text { To describe a baby who is smaller than the usual } \\
\text { amount for the number of weeks of pregnancy. Sga } \\
\text { babies usually have birth weights below the 10th } \\
\text { percentile for babies of the same gestational age. }\end{array}$ \\
\hline 3 & $\begin{array}{l}\text { Contraceptive } \\
\text { prevalence }\end{array}$ & $\begin{array}{l}\text { It is usually reported for married or in-union } \\
\text { women aged } 15 \text { to } 49 \text {. }\end{array}$ \\
\hline 4 & $\begin{array}{l}\text { Demand for } \\
\text { contraception is } \\
\text { satisfied }\end{array}$ & $\begin{array}{l}\text { The percentage of total demand for fp at any time } \\
\text { that is being satisfied by current contraceptive } \\
\text { use. Calculated by: satisfaction of demand for } \\
\text { fp = contraceptive prevalence rate (cpr) / (cpr }+ \\
\text { unmet need) }\end{array}$ \\
\hline 5 & Low weight for age & $\begin{array}{l}\text { Low weight for age is not defined in the source } \\
\text { document, however most are reported according } \\
\text { to the who global database on child growth and } \\
\text { malnutrition which uses a z-score cut-off point } \\
\text { of }<-2 \text { sd to classify low weight-for-age and low } \\
\text { height-for-age. Of note, the use of }-2 \text { z-scores } \\
\text { as a cut-off implies that } 2.3 \% \text { of the reference } \\
\text { population will be classified as malnourished } \\
\text { even if they are truly "healthy" individuals with } \\
\text { no growth impairment. Hence, } 2.3 \% \text { can be } \\
\text { regarded as the baseline or expected prevalence. }\end{array}$ \\
\hline
\end{tabular}

\section{References}

1. Rutstein SO (2005) Effects of preceding birth intervals on neonatal, infant and underfive years' mortality and nutritional status in developing countries: evidence from the 
demographic and health surveys. Int J Gynecol Obstet 89: S7-S24. [Crossref]

2. Norton M (2005) New evidence on birth spacing: promising findings for improving newborn, infant, child, and maternal health. Int J Gynaecol Obstet Off Organ Int Fed Gynaecol Obstet 89 Suppl 1: S1-6. [Crossref]

3. Cleland J, Bernstein S, Ezeh A, Faundes A, Glasier A, et al. (2006) Family planning: the unfinished agenda. Lancet Lond Engl 368: 1810-1827. [Crossref]

4. Glasier A, Gülmezoglu AM, Schmid GP, Moreno CG, Van Look PFA (2006) Sexual and reproductive health: a matter of life and death. Lancet Lond Engl 368: 1595-1607. [Crossref]

5. Jansen WH (2005) Existing demand for birth spacing in developing countries: perspectives from household survey data. Int J Gynaecol Obstet Off Organ Int Fed Gynaecol Obstet 89 Suppl 1:S50-60. [Crossref]

6. Contraceptive prevalence, any methods (\% of women ages $15-49) \mid$ Data. The World Bank. Published 2016.

7. Belize Multiple Indicator Cluster Survey 2011. November 2012.

8. The Situational Analysis of Children and Women in Belize 2011: An Ecological Review. July 2011.
9. Belize Multiple Indicator Cluster Survey 2015 Key Findings. August 2016

10. Belize Population and Housing Census: Country Report 2010. 2013.

11. Davidson CR, Billings D, Friedman D (2013) Understanding Family Planning in San Ignacio, Belize. J Glob Health 3:25-31.

12. Belize Basic Indicators 2010. 2011.

13. Health in the Americas 2012. 2012.

14. Health Statistics of Belize 2006 - 2010. October 2011.

15. Belize Healthcare System - Questions from US Healthcare Volunteers. Hillside Health Care International.

16. Belize Drug Formulary and Therapeutics Manual: Ninth Edition, 2009-2011. October 2008.

17. Pregnancy Spacing and Family Planning. USAID Knowledge Practices and Coverage Survey.

18. Johnson K, Posner S, Biermann J (2006) Recommendations to Improve Preconception Health and Health Care --- United States: A Report of the CDC/ATSDR Preconception Care Work Group and the Select Panel on Preconception Care. MMWR 55(RR06): 1-23.

Copyright: (C2017 Phillippi LM. This is an open-access article distributed under the terms of the Creative Commons Attribution License, which permits unrestricted use, distribution, and reproduction in any medium, provided the original author and source are credited. 